
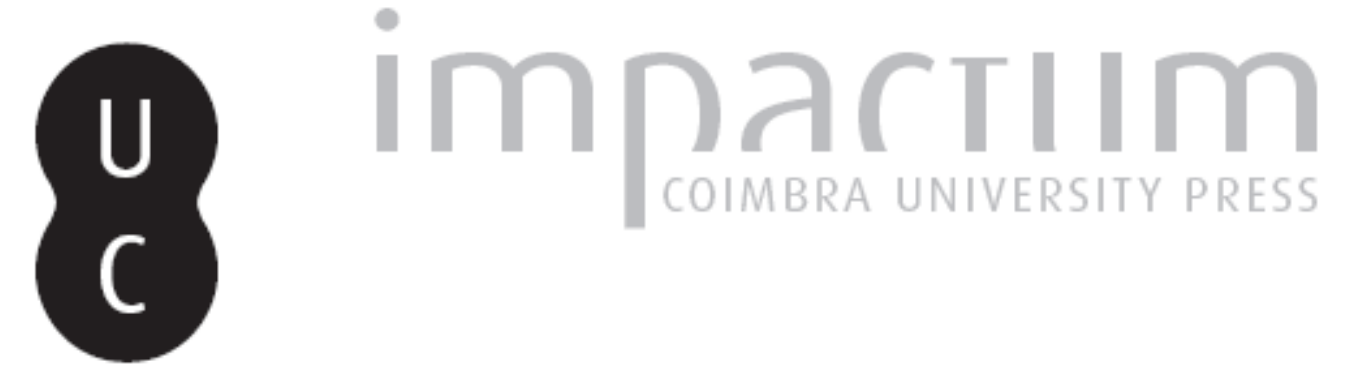

\title{
A burocracia régia e os seus oficiais no tempo de $\mathrm{D}$. Manuel I
}

Autor(es): $\quad$ Faria, Diogo

Publicado por: Imprensa da Universidade de Coimbra

URL persistente:

URl:http://hdl.handle.net/10316.2/35443

DOI:

DOI:http://dx.doi.org/10.14195/0870-4147_45_24

Accessed : $\quad$ 26-Apr-2023 13:51:59

A navegação consulta e descarregamento dos títulos inseridos nas Bibliotecas Digitais UC Digitalis, UC Pombalina e UC Impactum, pressupõem a aceitação plena e sem reservas dos Termos e Condições de Uso destas Bibliotecas Digitais, disponíveis em https://digitalis.uc.pt/pt-pt/termos.

Conforme exposto nos referidos Termos e Condições de Uso, o descarregamento de títulos de acesso restrito requer uma licença válida de autorização devendo o utilizador aceder ao(s) documento(s) a partir de um endereço de IP da instituição detentora da supramencionada licença.

Ao utilizador é apenas permitido o descarregamento para uso pessoal, pelo que o emprego do(s) título(s) descarregado(s) para outro fim, designadamente comercial, carece de autorização do respetivo autor ou editor da obra.

Na medida em que todas as obras da UC Digitalis se encontram protegidas pelo Código do Direito de Autor e Direitos Conexos e demais legislação aplicável, toda a cópia, parcial ou total, deste documento, nos casos em que é legalmente admitida, deverá conter ou fazer-se acompanhar por este aviso.

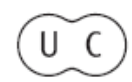




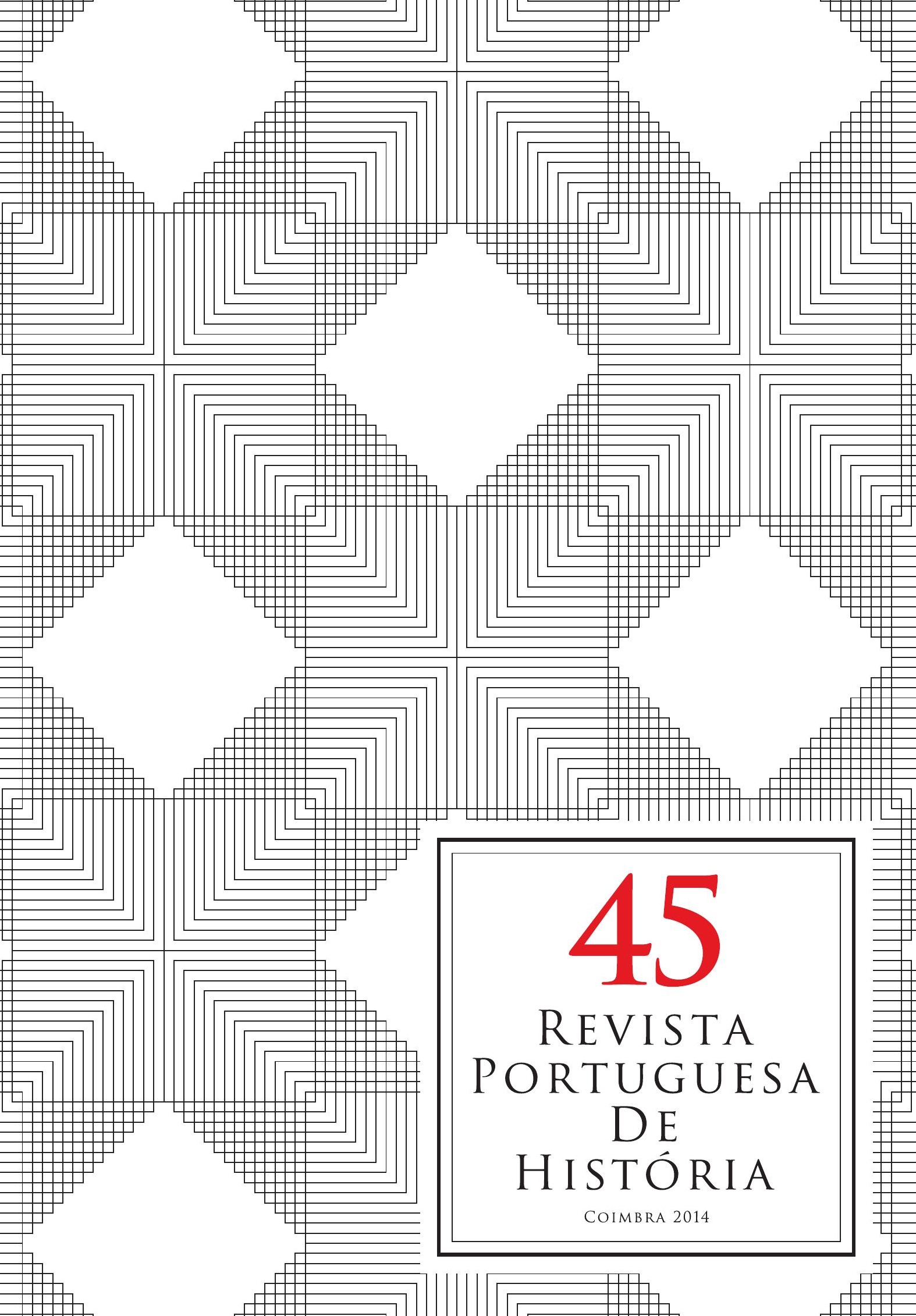




\title{
A burocracia régia e os seus oficiais no tempo de D. Manuel I
}

\section{The royal bureaucracy and its officers in the reign of King Manuel I}

\author{
DiOgO FARIA \\ Universidade do Porto, CEPESE, IEM-FCSH/UNL \\ diogopintofaria@gmail.com
}

\section{Resumo:}

A modernidade da administração central é uma das características que a historiografia costuma destacar do reinado de D. Manuel. Neste trabalho, tendo como base os registos de oito livros da Chancelaria do Venturoso, procura-se verificar se, na realidade, o Desembargo sofreu transformações significativas durante este período. Nesse sentido, tenta-se identificar novidades e permanências em aspetos como: a estrutura externa da Chancelaria; os conteúdos dos documentos; o peso de cada 'departamento' no seio da administração; o elenco dos cargos associados à burocracia.

\section{Palavras-chave:}

Chancelaria; burocracia régia; administração central; D. Manuel I; Portugal.

\section{Abstract:}

The modernity of the central government is one of the characteristics that historiography tends to highlight about the reign of King Manuel. This paper, based on the records of eight books of the Chancery of this king, seeks to determine whether, in fact, the royal administration undergone significant changes during this period. So, this work attempts to identify innovations and continuities in aspects such as: the external structure of the Chancery; the contents of the documents; the weight of each 'department' within the administration; the offices involved in the writing of the diplomas.

Keywords:

Chancery; royal bureaucracy; royal administration; King Manuel I; Portugal. 
Damião de Góis escreveu que foi "no mais alto, e prospero stado que se a hu Rei podia desejar" que D. Manuel I morreu, em Lisboa, em 13 de dezembro de 1521. Quando expirou, após 26 anos de reinado, o Venturoso era senhor do mar "desno streito de Gibraltar [...] atte ha China". Na sua Corte, onde abundavam riquezas "douro, prata speciarias, que lhe cadano vinhão de suas cõquistas", circulavam representantes dos mais notáveis reis e senhores da Europa (incluindo do papa), de África e da Ásia. A fama do monarca era notável e ultrapassava as fronteiras do reino. Um reino ao qual deixava paz e nove filhos legítimos ${ }^{1}$. Não se podia desejar mais nada.

$\mathrm{Na}$ linha do cronista, a maior parte da historiografia portuguesa tem caracterizado o reinado de D. Manuel I (1495-1521) como um tempo de muitas conquistas e muitas reformas. Se é inegável que durante este período ocorreram várias e importantes transformações, também não deixa de ser um facto que nem sempre se tem olhado para as realizações deste monarca com o devido afastamento crítico, procurando confrontar as ideias feitas com a realidade concreta expressa pela documentação ${ }^{2}$.

O objetivo deste trabalho é verificar, em linhas gerais, que modificações ocorreram na administração central do reino no tempo D. Manuel I, através da análise de oito livros da sua Chancelaria ${ }^{3}$. Este núcleo fundamental da governação será observado tendo em consideração dois aspetos fundamentais: a materialidade da Chancelaria, ou seja, os seus livros e documentos; e a sua componente humana, que reflete, em parte, a estrutura da administração central no tempo do Venturoso. Desta forma, após uma reflexão sobre a configuração externa da Chancelaria e a sua evolução, dar-se-á conta dos principais conteúdos dos documentos e do seu enquadramento em áreas de incidência governativa (Graça, Justiça, Fazenda e Administração Geral). De

\footnotetext{
${ }^{1}$ Damião de Góis, Crónica do Felicíssimo Rei D. Manuel, vol. 4, Coimbra, Imprensa da Universidade de Coimbra, 1926, p 195.

${ }^{2}$ Luís Miguel Duarte já o fez, em 2004, quando refletiu sobre o alcance da reforma dos forais de D. Manuel I, avançando com diversos indícios que apontam para o falhanço dos objetivos deste empreendimento. Cf. Luís Miguel Duarte, “Os «forais novos»: uma reforma falhada?", Revista Portuguesa de História, 36 (2004), p. 391-404.

${ }^{3}$ Serão retomados alguns dos principais dados e conclusões avançados na dissertação de mestrado que desenvolvi, na Universidade do Porto, sob orientação do Prof. Doutor Armando Luís de Carvalho Homem e co-orientação do Prof. Doutor Luís Miguel Duarte: Diogo Faria, $A$ Chancelaria de D. Manuel I. Contribuição para o estudo da burocracia régia e dos seus oficiais, dissertação de mestrado apresentada à Faculdade de Letras da Universidade do Porto, Porto, 2013. Nesse estudo, foram objeto de análise oito livros desta Chancelaria, correspondentes aos anos de 1496, 1504, 1512 e 1521, que integram, no total, 3157 diplomas emitidos nestes anos (não foram considerados os documentos relativos a outros anos que se encontram nos mesmos livros).
} 
seguida, verificar-se-á quem, para além do rei, foi responsável pela redação dos diplomas, identificando cargos, apontado as funções que lhes estavam associadas e verificando até que ponto a administração manuelina foi marcada por novidades.

\section{Os livros e os documentos}

Este ponto começa com a análise sumária da estrutura externa da Chancelaria de D. Manuel I. Organizada em livros, alguns destes em cadernos, e todos contendo centenas de atos emitidos em nome do Venturoso, importa tentar compreender até que ponto o que chegou aos nossos dias é representativo do que em tempos foi produzido. Para além disso, uma vez que esta Chancelaria se situa no termo de um século XV em que se assiste a um boom do número de registos da administração central, impõe-se procurar perceber se a organização externa desta documentação é reveladora de algum tipo de adaptação à nova realidade quantitativa da burocracia. Finalmente, cabe verificar se existem novidades no que toca ao conteúdo dos documentos emitidos durante este reinado e ponderar o peso de cada área de incidência governativa na produção burocrática da administração central.

\subsection{Subtrações, divisões, multiplicações...}

Quem se dirigir hoje ao Arquivo Nacional para consultar a Chancelaria de D. Manuel I encontra 47 livros, um escrito em papel, os restantes em pergaminho. Nem sempre foi assim. Em 1532, Tomé Lopes, Guarda-mor da Torre do Tombo, a pedido do rei D. João III, elaborou um inventário da documentação preservada no arquivo do reino ${ }^{4}$. Da longa lista de tomos e de escrituras avulsas fazem parte 71 livros de registos do tempo do Venturoso, todos "encadernados, cubertos de coyro de vaca cortido"s. À primeira vista, parecem ter-se preservado cerca de $65 \%$ dos volumes. Se olharmos ao número de fólios que existiam em 1532 e aos que existem hoje, a realidade é menos feliz: apenas $58 \%$ da documentação chegou aos nossos dias.

${ }^{4}$ Documento registado em Arquivo Nacional Torre do Tombo (ANTT), Chancelaria de D. Manuel I (CDM), Livro 18, fl. 131, e publicado em: José Pessanha, "Uma rehabilitação historica. Inventários da Torre do Tombo no século XVI", Archivo Historico Portuguez, III (1905), p. 287-303, maxime p. 299-303.

5 José Pessanha, “Uma reabilitação histórica...”, cit., p. 299-300. 
O que se poderá ter passado com os registos da administração central do Venturoso, durante os cinco séculos que medeiam a sua produção e a atualidade, que justifique a sua não conservação integral? Várias coisas: i) podem ter sido pura e simplesmente eliminados, porque considerados inúteis, quando copiados para a Leitura Nova; ii) podem ter sido levados para Espanha, durante o período filipino ${ }^{6}$; iii) podem ter sido destruídos pelo terramoto de 1755 (à falta de melhor explicação, o eterno culpado por muitas das lacunas documentais que afligem os historiadores portugueses...), que fez ruir a Torre do Tombo. Mas a história destes livros não é apenas feita de subtrações. A realidade é mais complexa: eles foram objeto de divisões, que originaram multiplicações. Tomemos os diplomas relativos a 1496 como exemplo.

Segundo o inventário de Tomé Lopes, em 1532 existiam dois tomos de registos emitidos nesse ano, que perfaziam um total de 786 fólios. Atualmente, conservam-se seis livros que dizem respeito a esse ano, que totalizam 679 folhas. Ou seja: houve uma multiplicação dos livros, mas uma divisão da documentação por mais volumes. Na origem disso pode ter estado o terramoto (lá está: é quase sempre o suspeito número um). Na sequência do sismo, vários livros ficaram bastante danificados, especialmente as suas encadernações. Nos anos seguintes, assistiu-se a um processo de reorganização do arquivo em geral e de certa documentação em particular, não se tendo tido a preocupação de restituir aos diplomas a sua ordem original ${ }^{7}$. Sendo assim, é bastante verosímil que, por essa altura, os livros ainda existentes da Chancelaria de D. Manuel I tenham sido reencadernados e que os seus cadernos tenham sido reagrupados em volumes de menor dimensão.

Em suma: a quantidade de registos da Chancelaria do Venturoso de que dispomos é consideravelmente inferior à que foi produzida entre 1495 e 1521; para além disso, os livros que hoje podemos consultar não preservam a sua estrutura externa original. Todo o investigador deve ter presente, portanto, que ao trabalhar com estes registos está a lidar com uma amostra deformada da documentação emitida por D. Manuel I.

${ }^{6}$ Hipótese abordada em: Fernando Portugal, "A Chancelaria de D. Manuel”, Ethnos, VI (1969), p. 261-270, maxime p. 264-265.

${ }^{7}$ Cf. Fernanda Ribeiro, "Como seria a estrutura primitiva do Arquivo da Casa da Coroa (Torre do Tombo)?" in Luís Adão da Fonseca, Luís Carlos Amaral, Maria Fernanda Ferreira Santos (coord.), Os Reinos Ibéricos na Idade Média, vol. 3, Porto, FLUP, 2003, p. 1401-1414, maxime p. 1401-1402. 


\subsection{Textos velhos em livros novos}

Inovadora quanto à forma como eram organizados os livros de registos dos diplomas régios, a Chancelaria de D. Manuel I é, contudo, tradicional no que toca ao conteúdo dos seus textos. Esta aparente contradição só à primeira vista pode parecer surpreendente, uma vez que se enquadra perfeitamente na evolução que a documentação régia vinha sofrendo desde reinados anteriores. Vejamos cada um dos aspetos.

A comparação dos livros de registos relativos a 1496 com aqueles que contêm os atos emitidos em 1504 permite desde logo detetar uma das principais inovações desta Chancelaria: o surgimento de volumes especializados por assuntos. Enquanto no primeiro ano completo do reinado as espécies documentais de cada tomo são muito diversificadas, em 1504 há um livro para provimentos, um livro para doações e um livro para privilégios. A especialização da Chancelaria em determinadas áreas não é uma novidade, sendo uma consequência do boom documental do século XV, mas apenas no tempo do Venturoso isso se reflete materialmente no modo como os livros eram organizados. É ainda durante este reinado que surge o primeiro volume da Chancelaria em papel e que os tomos constituídos por cadernos autónomos que eram cosidos e encadernados dão lugar a volumes únicos de registos.

Olhando aos conteúdos dos documentos, é mais complicado encontrar novidades. Os atos analisados foram classificados em função da tipologia definida por Armando Luís de Carvalho Homem em $O$ Desembargo Régio ${ }^{8}$ e desenvolvida em trabalhos por si orientados, como a tese de doutoramento de Judite Gonçalves de Freitas ${ }^{9}$. Apesar de terem sido introduzidas algumas nuances face à matriz original ${ }^{10}$, não se detetou o surgimento de espécies documentais absolutamente novas. Este facto é compreensível, à luz da tendência das últimas décadas do século XV para o empobrecimento tipológico dos atos da Chancelaria, impulsionado pela multiplicação de instâncias de registo e

${ }^{8}$ Armando Luís de Carvalho Homem, O Desembargo Régio (1320-1433), Porto, Instituto Nacional de Investigação Científica, 1990, p. 63-95.

9 Judite A. Gonçalves de Freitas, "Teemos por bem e mandamos". A burocracia régia e os seus oficiais em meados de Quatrocentos (1438-1460), vol. I, Cascais, Patrimonia, 2001, p. 33-85.

${ }^{10}$ Ajustou-se a designação de alguns tipos de cartas e individualizaram-se outros. O quadro classificativo da documentação completo, assim como a caracterização de cada tipo de carta e a análise do seu peso no âmbito dos atos compulsados, pode ser consultado em: Diogo Faria, $A$ Chancelaria de D. Manuel I..., cit., p. 23-47. 
pela cada vez maior especialização da burocracia ${ }^{11}$. No entanto, durante este reinado assiste-se a uma viragem na representatividade dos diferentes 'departamentos' da administração no seio do Desembargo régio.

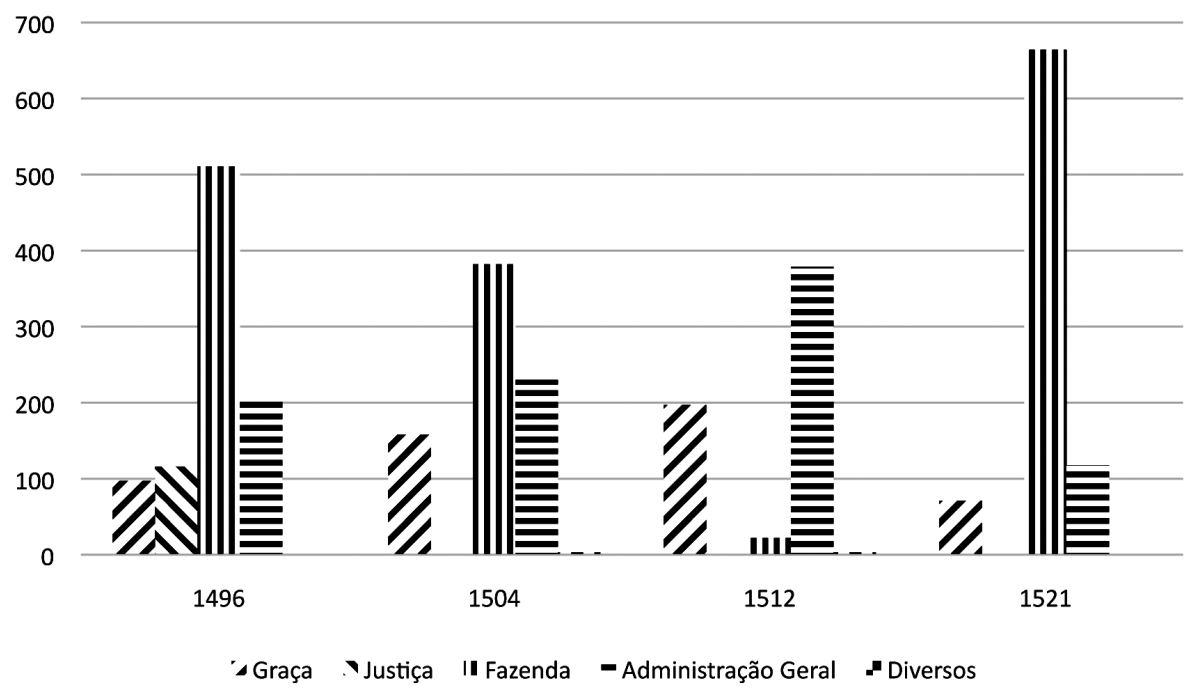

Gráfico 1 - Áreas de incidência governativa da documentação régia emitida em $1496,1504,1512$ e 1521

A análise do gráfico permite constatar que a Fazenda era o 'departamento' da administração manuelina que mais se destacava: 50,02\% da documentação analisada enquadra-se neste âmbito. São as 1168 cartas de provimento de ofícios registadas nos oitos livros compulsados que mais determinam a dimensão deste valor. Este número torna-se ainda mais impressionante se for comparado com tempos anteriores: entre os 20655 documentos que Manuela Mendonça coligiu para o reinado de D. João II, o peso da Fazenda não atingia sequer os $9 \%{ }^{12}$.

${ }^{11}$ Armando Luís de Carvalho Homem, Luís Miguel Duarte, Eugénia Pereira da Mota, "Percursos na burocracia régia (séculos XII-XV)" in Francisco Bethencourt, Diogo Ramada Curto (ed.), A Memória da Nação [atas do colóquio], Lisboa, Sá da Costa, p. 403-423, maxime p. 409-410.

${ }^{12}$ Manuela Mendonça, D. João II. Um percurso humano e político nas origens da modernidade em Portugal, 2 ${ }^{\mathrm{a}}$ edição, Lisboa, Editorial Estampa, 1995, p. 290. 
Segue-se, em termos de importância quantitativa, a Administração Geral, que representa perto de $30 \%$ dos atos exarados. É o domínio da Defesa que mais contribui para este valor, sendo também assinalável a sua evolução desde o reinado de D. João II, quando correspondia a cerca de $7 \%$ dos diplomas emitidos ${ }^{13}$.

A Graça, cujas espécies documentais totalizam cerca de 17\% dos diplomas coligidos, é um 'departamento' cuja presença dos volumes da Chancelaria é constante, sofrendo poucas variações: para cada um dos anos estudados há normalmente entre cerca de 100 e 200 atos enquadráveis neste âmbito. Neste conjunto de textos, destacam-se os privilégios de cariz social e familiar (correspondentes a cerca de $7 \%$ da documentação total). Seguem-se, em termos de importância quantitativa, os privilégios em geral (cerca de 5\%), os privilégios de natureza profissional (3\%) e os privilégios relacionados com a Igreja (1\%).

A Justiça é um setor da administração que se eclipsa dos registos Chancelaria durante o reinado de D. Manuel I. Se nos dois livros relativos a 1496 ainda se encontram 116 cartas de perdão, nos outros seis volumes estudados não há uma única para amostra. Ao que se deve este ocaso? Naturalmente, o Venturoso não deixou de conceder perdões. Em 1517, D. Manuel até promulgou um regimento sobre perdões ${ }^{14}$. O mais plausível é que as cartas deste tipo emitidas em 1504, 1512 e 1521 tenham sido registadas em livros próprios que não chegaram até nós. Um olhar mais atento sobre outros volumes desta Chancelaria e a comparação com a organização da Chancelaria de D. João III (que tinha livros só de perdões) poderão contribuir para um esclarecimento mais cabal deste aspeto.

\section{Os que mandam escrever}

É do conhecimento geral que o escatocolo dos documentos régios medievais inclui uma de duas fórmulas: el-rei o mandou, fulano (escrivão) a fez; el o rei mandou por fulano (redator), sicrano (escrivão) a fez. São estas expressões que nos permitem apurar se foi o monarca que ordenou diretamente ao escriba a redação de determinado diploma ou se houve um intermediário entre a vontade régia e a materialidade do ato. Este panorama não muda no reinado de D. Manuel I. Temos, portanto, dois tipos de documentos: os que são redigidos

\footnotetext{
${ }^{13}$ Manuela Mendonça, D. João II..., cit., p. 290-291.

${ }^{14}$ Publicado em Luís Miguel Duarte, Justiça e Criminalidade no Portugal Medievo (1459-1481), Lisboa, Fundação Calouste Gulbenkian e Fundação para a Ciência e a Tecnologia, 1999, p. $726-732$.
} 
pelo rei e os que têm um oficial como redator. Vejamos que tipos de documentos eram subscritos por quem e que oficiais do Desembargo estavam envolvidos na preparação dos textos, tentando descortinar, através da identificação dos seus cargos, a estrutura do governo associada à Chancelaria .

\subsection{O rei}

Antes de verificarmos quantos atos e que diplomas eram subscritos pelo Venturoso, aproveitemos um relato de Damião de Góis para nos aproximarmos do que seria o quotidiano do rei no que toca ao exercício de tarefas administrativas ${ }^{15}$.

A sexta-feira seria o momento da semana privilegiado para o despacho. Conta-nos o cronista que só quando esteve doente é que $\mathrm{D}$. Manuel não aproveitou esse dia para se inteirar dos assuntos da Casa da Suplicação, ouvindo presos e participando na elaboração de sentenças. Depois de comer, despachava ordinariamente com os Desembargadores do Paço, sem nunca deixar uma petição por desembargar. As petições da Câmara e da Fazenda eram levadas ao monarca pelos respetivos escrivães. O momento em que o rei assinava os diplomas tinha caráter solene e, frequentemente, era público: ladeando o Venturoso, de joelhos, sentavam-se o Escrivão da Puridade e um dos Vedores da Fazenda; à volta da mesa onde o rei autografava os documentos, também de joelhos, encontravam-se os escrivães da Câmara e da Fazenda. Por vezes, D. Manuel promovia audiências públicas, onde ouvia todos os que lhe quisessem falar. Igualmente nestas ocasiões, era acompanhado pelo Escrivão da Puridade e por um dos Vedores da Fazenda.

O monarca também aproveitava alguns momentos que poderiam ser de lazer para despachar. Quando se passeava de galeota pelo rio, fazia-se acompanhar de um oficial, com quem ia desembargando. Nesta e noutras alturas, a música assumia-se como um elemento importante no dia-a-dia do rei, que se rodeava de tocadores de vários instrumentos nas mais diversas ocasiões.

Conhecida uma parte do quotidiano régio, debrucemo-nos sobre a documentação que tinha o rei como subscritor, ou seja, aquela cujo escatocolo integra a fórmula "El-rei o mandou, fulano a fez".

D. Manuel I foi, teoricamente, responsável pela redação de cerca de $42 \%$ dos diplomas compulsados. Na realidade, é pouco verosímil, por exemplo, que o Venturoso tenha transmitido diretamente aos escribas as centenas de

${ }^{15}$ Damião de Góis, Crónica do Felicíssimo..., cit., p. 197-203. 
concessões do privilégio de espingardeiro ou de besteiro do monte que se encontram no livro 7 da sua Chancelaria. É impossível distinguir, no entanto, os atos em que o rei interveio diretamente daqueles em que isso não aconteceu, apesar de não registarem qualquer intervenção redatorial intermédia.

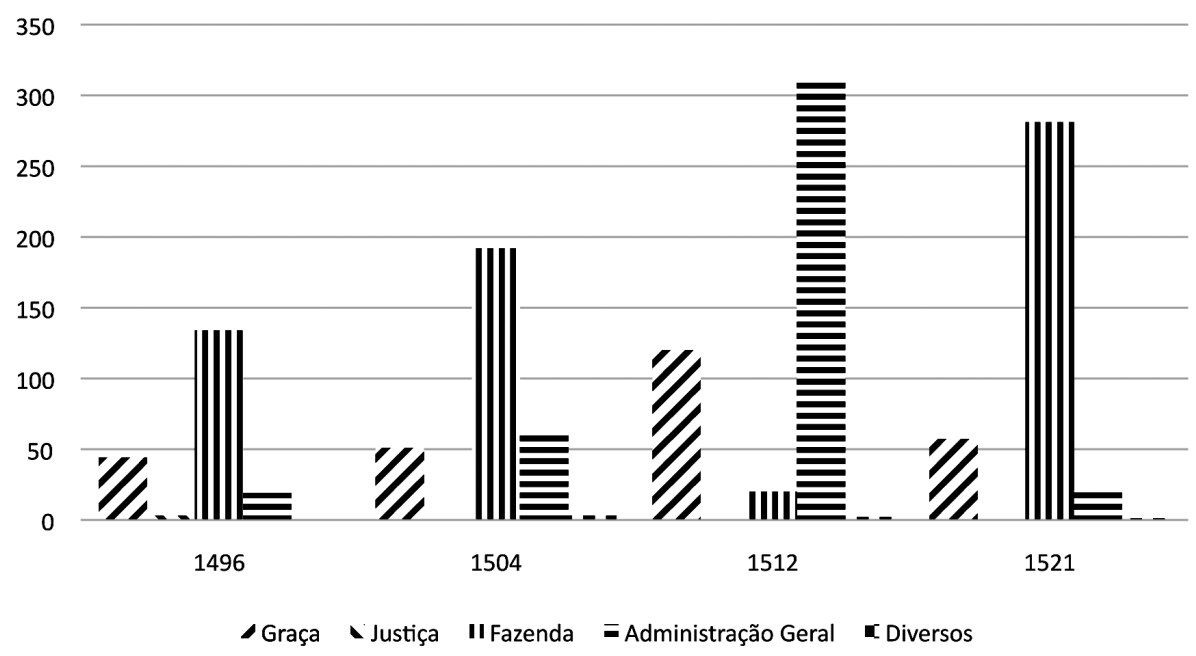

Gráfico 2 - Áreas de incidência governativa da documentação subscrita pelo rei

O gráfico demonstra que D. Manuel interveio diretamente na elaboração de diplomas enquadráveis em todas as categorias documentais definidas no ponto anterior, mas muito mais numas do que noutras. Em termos absolutos, foi no domínio da Fazenda que a interferência do rei mais se fez sentir, apesar de assumir um valor quase insignificante em $1512^{16}$. Reflete-se, dessa forma, a crescente importância deste setor da administração na Chancelaria, como que substituindo o peso que a Justiça assumiu na documentação régia ao longo da maior parte do século XV e que, no reinado de D. Manuel, era já muito baixo. A subscrição de atos relacionados com a Graça e a Administração Geral atinge em 1496, 1504 e 1521 valores muito próximos. Em 1512, é elevadíssimo o número de cartas da Administração Geral que supostamente foram emanadas

${ }^{16}$ Nem podia ser de outra forma, uma vez que apenas 22 dos 601 documentos coligidos desse ano se enquadram no domínio da Fazenda. 
diretamente do rei, correspondendo a maior parte delas a privilégios de natureza militar.

O cenário até agora traçado é um pouco diferente se, em vez de olharmos aos valores absolutos das cartas de subscrição régia, atendermos aos valores relativos em função de cada categoria documental.

\begin{tabular}{|c|c|c|c|}
\cline { 2 - 4 } \multicolumn{1}{c|}{} & $\begin{array}{c}\text { N. }{ }^{\circ} \text { total de } \\
\text { cartas }\end{array}$ & $\begin{array}{c}\text { Cartas de } \\
\text { subscrição régia }\end{array}$ & $\begin{array}{c}\text { \% de cartas de } \\
\text { subscrição régia }\end{array}$ \\
\hline Graça & 523 & 273 & $52,20 \%$ \\
\hline Justiça & 116 & 3 & $2,59 \%$ \\
\hline Fazenda & 1579 & 627 & $39,71 \%$ \\
\hline Administração Geral & 932 & 410 & $43,99 \%$ \\
\hline Diversos & 7 & 6 & $85,71 \%$ \\
\hline Total & 3157 & 1319 & $41,78 \%$ \\
\hline
\end{tabular}

Quadro 1 - Distribuição das cartas de subscrição régia por área de incidência governativa

Foi no domínio da Justiça que a interferência direta do monarca na elaboração dos diplomas menos se fez sentir: das 116 cartas de perdão coligidas, apenas três não foram redigidas por intermédio de uma dupla de Desembargadores. $\mathrm{O}$ peso da intervenção régia é relativamente equilibrado nos setores da Graça, da Fazenda e da Administração Geral, variando entre os cerca de $40 \%$ e os $52 \%$. No entanto, no âmbito desse equilíbrio, há nuances que se distinguem daquilo que foi possível observar quando se olhou aos valores absolutos. Sendo o 'departamento' ao qual corresponde a parte mais significativa dos atos emitidos diretamente pelo Venturoso, a Fazenda não é o domínio da documentação em que o peso da interferência do rei mais se faz sentir. Era no âmbito da Graça que a redação dos diplomas mais vezes dispensava a intervenção de intermediários (52\% do total). Tendo em conta que as cartas associadas a esse setor da produção documental correspondiam, fundamentalmente, ao exercício da liberalidade do monarca, não admira que assim fosse.

Em síntese: D. Manuel foi um rei que interveio diretamente na preparação de cerca de $42 \%$ dos diplomas emitidos em seu nome. Despachando um pouco 
de tudo, eram os atos relativos à Fazenda que mais vezes mandava os escribas materializarem, apesar de ser no domínio da Graça que o peso relativo da sua intervenção mais se fazia sentir.

\subsection{Os oficiais redatores}

Foram vários os oficiais que foram responsáveis pela redação de diplomas em nome de D. Manuel I. Os cargos exercidos por esses homens enquadram-se em setores da administração tão diversificados como a Chancelaria e a Justiça, a Fazenda, a Defesa e a Caça, e a Física. Tendo em conta estes 'departamentos', vejamos que ofícios eram estes, qual o seu enquadramento normativo $^{17}$, e que documentação se lhes encontrava associada.

\subsubsection{Ofícios da Chancelaria e da Justiça}

No âmbito da Chancelaria e da Justiça exerceram funções redatoriais o Chanceler-mor, os Desembargadores do Paço e das Petições, os Desembargadores do Agravo e os Corregedores da Corte.

O Chanceler-mor, cargo regulamentado pelas Ordenações Afonsinas e pelas Ordenações Manuelinas e segundo ofício da Casa da Suplicação, tinha como principal função a verificação de todas as cartas que eram emitidas pelo rei. Para além disso, competia-lhe despachar vários tipos de diplomas: apresentação de clérigos a igrejas do padroado régio; cartas de nomeação de tabeliães; cartas de provimento de diversos ofícios das administrações central, periférica e local; cartas relacionadas com o Estudo Geral; cartas de esmoler; treslados de ordenações e de todos os documentos emitidos pelo rei. O Chanceler também era responsável por dar juramento a vários oficiais régios ${ }^{18}$.

${ }^{17}$ Recorde-se que durante o reinado de D. Manuel I estiveram em vigor, para além de diversos regimentos extravagantes, as Ordenações Afonsinas (até 1512) e as Ordenações Manuelinas (1512 ss.). O atribulado processo de publicação das Ordenações Manuelinas, que conheceram diferentes sistemas (e não apenas edições) durante o reinado do Venturoso tem vindo a ser estudado por João Alves Dias. Sobre as mais recentes novidades neste domínio, cf. João José Alves Dias, $A s$ Ordenações Manuelinas 500 anos depois: os dois primeiros sistemas (1512-1519), Lisboa, Centro de Estudos Históricos da Universidade Nova de Lisboa, Biblioteca Nacional de Portugal, 2012.

${ }^{18}$ Ordenações Afonsinas, 5 volumes, nota de apresentação de Mário Júlio de Almeida Costa, nota textológica de Eduardo Borges Nunes. Lisboa, Fundação Calouste Gulbenkian, 1985, L. I, tít. II, p. 17-23 (a partir daqui, OA); Ordenações Manuelinas, 5 volumes, introdução de João José Alves Dias, Lisboa, Centro de Estudos Históricos da Universidade Nova de Lisboa, 2002, L. I, tít. II, fls. VIIv-XIv (a partir daqui, OM1512-1513); Ordenações Manuelinas. 5 volumes, 
A análise da documentação redigida pelos Chanceleres-mores durante os quatro anos estudados não contraria os preceitos normativos. O titular desse ofício e os seus substitutos temporários foram responsáveis pela redação de cerca de 19,7\% dos diplomas coligidos. Foi nos domínios da Fazenda e da Administração Geral que a sua ação mais se desenvolveu, destacando-se as centenas de cartas de tabelião e de provimentos de ofícios (normalmente relacionados com a escrita) despachadas por quem ocupava este cargo. No campo da Graça, coube ao Chanceler-mor subscrever as cartas de apresentação de clérigos a igrejas do padroado régio.

Na documentação analisada surgem como redatores de diplomas dois tipos de Desembargadores: os do Paço e Petições e os dos Agravos. A progressiva distinção entre estes dois tipos de magistrados é patente à medida que vão sendo preparados novos códigos legislativos: nas Ordenações Afonsinas há um título sobre os Desembargadores do Paço ${ }^{19}$; no primeiro sistema das Ordenações Manuelinas o terceiro título é dedicado aos "Desembargadores do Paaço que conhecem das petiçoões e agravos em nossa casa da sopricaçã" na edição definitiva do código do Venturoso há um título sobre os Desembargadores do Paço e outro sobre os Desembargadores do Agravo ${ }^{21}$. Uma vez que no escatocolo dos atos coligidos estão presentes as duas designações, optou-se por tratar os dois ofícios em separado.

Segundo o sistema definitivo das Ordenações Manuelinas, cabia aos Desembargadores do Paço, que atuavam normalmente aos pares, despachar petições do domínio da Graça. Eram, juntamente com o monarca, responsáveis pelo desembargo dos perdões. Para além disso, podiam passar diversos tipos de cartas: privilégios e liberdades (desde que não colidissem com os direitos, rendas e tributos régios); legitimações; restituições de fama; fintas; provimentos de ofícios de sesmarias; confirmações de eleições de juízes ordinários e dos órfãos; emancipações, entre outras ${ }^{22}$. Nas Ordenações Afonsinas e na primeira edição do código de D. Manuel previa-se ainda que deliberassem sobre os agravos de sentenças que a eles chegassem, no que seriam auxiliados pelo Terceiro dos Agravos $^{23}$.

nota de apresentação de Mário Júlio de Almeida Costa, Lisboa, Fundação Calouste Gulbenkian, 1984, L. I, tít. II, p. 35-47 (a partir daqui, OM1521).

${ }^{19}$ OA, L. I, tít. IV, p. 26-37.

${ }^{20} \mathrm{OM} 1512-1513$, L. I, tít. IV, fls. XVIv-XX.

${ }^{21}$ OM1521, L. I, títs. III-IV, p. 48-64.

${ }^{22}$ OM1521, L. I, tít. III, p. 48-54.

${ }^{23}$ OA, L. I, tít. IV, p. 26-27; OM1512-1513, L. I, tít. IV, fl. XVIv. 
Os Desembargadores do Paço foram responsáveis pela redação de 347 dos diplomas coligidos, o que corresponde a cerca de $11 \%$ do total. A sua intervenção foi particularmente relevante no domínio da Justiça, tendo subscrito 113 cartas de perdão em 1496. De resto, a sua atividade burocrática vai ao encontro das prescrições normativas sobre o ofício: estes magistrados intervêm sobretudo no âmbito da Graça, sendo os principais redatores de cartas de legitimação, estalajadeiro, carreteiro, entre outras, e intervindo também na preparação de diplomas conferentes de privilégios de diversa índole.

Aos Desembargadores do Agravo competia deliberar sobre os agravos de sentenças proferidas por certos magistrados (Corregedores da Corte, Ouvidores e Sobrejuízes $)^{24}$. A intervenção redatorial destes oficiais na documentação coligida é diminuta: subscrevem apenas quatro cartas (duas de perdão, uma de estalajadeiro e um provimento de ofício), todas datadas de março de 1496 e registadas no Livro 26 da Chancelaria de D. Manuel I. Este facto não é de estranhar, tendo em conta que a estes magistrados competia fundamentalmente proferir sentenças, espécie documental de que não se encontrou qualquer exemplo nos oito livros estudados.

Finalmente, os Corregedores. O ofício de Corregedor desdobrou-se entre a promulgação das Ordenações Afonsinas e a das Ordenações Manuelinas: o cargo unipessoal das Ordenações do Africano deu origem aos ofícios de Corregedor da Corte dos feitos crimes e Corregedor da Corte dos feitos cíveis na coletânea do Venturoso.

Tradicionalmente, competia ao Corregedor da Corte desempenhar as mesmas funções dos Corregedores das comarcas nos locais onde se encontrasse o monarca ou a Casa da Suplicação. As suas principais atribuições eram: julgar diversos tipos de feitos; fiscalizar contas de concelhos, albergarias, hospitais e órfãos; determinar o conserto de bens de concelhos, órfãos, hospitais e albergarias que se encontrassem danificados; verificar o estado dos castelos; nomear Corregedores e Meirinhos de comarcas; emitir diversos tipos de $\operatorname{cartas}^{25}$.

Com o desdobramento dos ofícios, passou a caber ao Corregedor da Corte dos feitos crimes o julgamento de todos os crimes que ocorressem no local onde se encontrasse a Casa da Suplicação e no perímetro de cinco léguas que

${ }^{24}$ Existiam Desembargadores do Agravo da Casa da Suplicação e Desembargadores do Agravo da Casa do Cível, que desempenhavam funções equivalentes em cada um dos tribunais. Cf. OM1512-1513, L. I, tít. XXIV, fl. LIII-LIIIv; OM1521, L. I, tít. XXXI, p. 214-215.

${ }^{25}$ OA, L. I, tít. V, p. 37-57. 
a envolvia ${ }^{26}$. Ao Corregedor da Corte dos feitos cíveis cabia desempenhar as funções do Corregedor da comarca igualmente na zona onde se encontrasse a Corte ${ }^{27}$.

A intervenção destes oficiais na subscrição de diplomas registados nos livros analisados da Chancelaria régia foi bastante escassa. Martim Pinheiro, Corregedor dos feitos crimes, subscreveu em 1496 e em 1504 uma carta de tabelião e duas cartas de provimento de ofício. João Cotrim, Corregedor dos feitos cíveis, foi responsável pela redação de uma carta de doação de bens e direitos em 1504.

\subsubsection{Ofícios da Fazenda}

Pelo final do século XV, a Fazenda já era a área de incidência governativa que mais se destacava no âmbito da Chancelaria, colocando um ponto final na supremacia da Justiça. O crescimento deste domínio, no entanto, não implicou a criação de novos cargos superiores: o essencial do despacho relacionado com esta matéria continuou nas mãos dos Vedores da Fazenda.

O ofício de Vedor da Fazenda foi regulamentado por três normas diferentes durante o reinado de D. Manuel I: pelas Ordenações Afonsinas ${ }^{28}$, pelo primeiro sistema das Ordenações Manuelinas ${ }^{29}$ e por um regimento avulso, promulgado em $1516^{30}$. Vejamos caso a caso e acompanhemos a complexificação desta legislação.

O código afonsino determinava que a ação dos Vedores da Fazenda incidia particularmente sobre três domínios: o "arrendamento dos direitos régios e das rendas do Reino"; o "conhecimento dos feitos das sisas"; e a redação de vários tipos de cartas (contratos de exploração, doações, provimentos de ofícios que não fossem da área da Justiça, etc.) ${ }^{31}$.

O regimento contido na primeira edição das Ordenações Manuelinas começa por enumerar as características que idealmente teriam os homens que desempenhassem estas funções: "honrados e de bõas e saãs cõsciencias", deveriam ter muito cuidado ao olhar por todas as coisas que pertencessem ao

${ }^{26}$ OM1512-1513, L. I, tít. V, fl. XX-XXIIIv; OM1521, L. I, tít. V, p. 64-76.

${ }^{27}$ OM1512-1513, L. I, tít. VI, fl. XXIIIv-XXIVv; OM1521, L. I, tít. VI, p. 76-79.

${ }^{28}$ OA, L. I, tít. III, p. 23-25.

${ }^{29}$ OM1512-1513, L.I, tít. III, fl. XIv-XVI.

${ }^{30}$ Publicado em: José Roberto Monteiro de Campos Coelho e Sousa, Systema, ou Colleção dos Regimentos Reaes..., vol. I, Lisboa, Oficina de Francisco Borges de Sousa, 1783, p. 1-36.

${ }^{31}$ OA, L. I, tít. III, p. 23-25. Cf. a síntese deste articulado em Armando Luís de Carvalho Homem, O Desembargo Régio..., cit., p. 120. 
rei. E tinham de ser ricos, para que não se deixassem corromper nem tivessem necessidade de executar funções que os desviassem do serviço ao monarca. De seguida, são indicadas as principais tarefas associadas ao cargo, que não diferem muito das disposições das Ordenações Afonsinas. No entanto, o código manuelino é mais detalhado no que toca à descrição dos procedimentos administrativos. A maior inovação reside na determinação de que os Vedores da Fazenda elaborassem "huum livro de tombo de todalas rendas e dereitos que pertencem aa coroa do regno"32.

O regimento dos Vedores da Fazenda de 1516 foi de tal modo importante que este cargo nem seria regulamentado no terceiro sistema do código manuelino. Os requisitos para o exercício da função continuavam a ser os mesmos. Uma vez mais, as competências atribuídas a estes oficiais não são grandemente alteradas. Cabia-lhes: controlar a fazenda régia (bens e rendas); superintender um conjunto alargado de oficiais; desembargar vários tipos de cartas; prover inúmeros ofícios; exercer a função de juiz em casos de apelação relacionados com a Fazenda. Neste documento é de novo salientada a necessidade de ser elaborado um tombo de todas as propriedades e direitos régios, que deveria ser concretizado pelos Contadores das comarcas sob a orientação dos Vedores da Fazenda. A complexificação dos procedimentos administrativos continua a aumentar, como Maria Leonor García da Cruz já demonstrou ${ }^{33}$.

Os Vedores da Fazenda foram responsáveis pela redação de 563 dos documentos analisados, o que corresponde a cerca de $18 \%$ do total. A esmagadora maioria da intervenção burocrática destes oficiais aconteceu no domínio da Fazenda, sendo residual a sua participação na subscrição de atos enquadráveis no âmbito da Graça régia ou da Administração Geral. Os principais tipos de cartas que passaram pelas mãos destes oficiais são: contratos de exploração, doações de bens e direitos e provimentos de ofícios.

Também se enquadram no domínio da Fazenda as funções redatoriais exercidas pelo Almotacé-mor e pelo Vedor-mor das obras, terças e resíduos, cuja intervenção na preparação de diplomas é muito mais escassa do que a dos Vedores.

O Almotacé-mor era um oficial que acompanhava sempre o monarca e o seu séquito na sua itinerância. A sua principal função era garantir o abastecimento da Corte de vinho, carne, peixe, pão e outros mantimentos. Para além

${ }^{32}$ OM1512-1513, L. I, tít. III, fl. XIv-XVI.

${ }^{33}$ Cf. a síntese do regimento que esta autora publicou em: Maria Leonor García da Cruz, A Governação de D. João III: a Fazenda Real e os seus Vedores, Lisboa, Centro de História da Universidade de Lisboa, 2001, p. 55-74. 
disso, no espaço onde exercia a sua jurisdição (o local onde se encontrava a Corte e a área de cinco léguas que o rodeava), competia-lhe: conceder privilégios de isenção de direitos de circulação a quem contribuísse para o abastecimento real; fazer cumprir posturas sobre esterqueiras, canos, chafarizes, fontes e poços; controlar a atividade dos almotacés; fiscalizar os preços, os pesos e o tamanho do pão nos mercados e açougues; garantir a limpeza dos locais onde passaria o rei; mandar arranjar caminhos, calçadas e pontes por onde o monarca circulasse ${ }^{34}$.

Limita-se à redação de uma carta a intervenção burocrática do Almotacé-mor nos livros que foram estudados: em 1512, Nuno Manuel concedeu um privilégio a um carniceiro da Corte.

O ofício de Vedor-mor das obras remonta ao reinado de D. João I. Segundo Miguel Soromenho, este cargo tinha uma "projeção pouco mais do que honorífica", limitando-se a ação do seu titular à "manutenção dos paços reais" ${ }^{35}$. É verosímil, no entanto, que não fosse tanto assim. Durante o século XV, existiram vedores das obras de cidades e de comarcas. Em alguns casos (por exemplo, o do Porto) esses oficiais eram nomeados pelo concelho, noutros (como Braga no período de jurisdição régia) pelo rei ${ }^{36}$. Era ao Vedor-mor das obras que competia o provimento desses cargos. Para além disso, como já deu conta Saul Gomes, cabia a este oficial a gestão e fiscalização das obras públicas em geral ${ }^{37}$.

A participação do Vedor-mor das obras, Nuno Martins da Silveira, na subscrição de documentos da Chancelaria régia nos anos em apreço é escassa. Limita-se a 11 cartas, emitidas em 1504 e em 1521: dois contratos de exploração e nove provimentos de ofício (todos de vedores ou escrivães das obras).

${ }^{34}$ OM1512-1513, L. I, tít. XII, fl. XXXI-XXXVIv; OM1521, L. I, tít. XV, p. 113-134; Ruy d'Abreu Torres, “Almotacé" in Joel Serrão (dir.), Dicionário de História de Portugal, vol. I, Porto, Figueirinhas, 2006, p. 121.

${ }^{35}$ Miguel Soromenho, "A administração da arquitetura: o Provedor das Obras Reais em Portugal no século XVI e na $1^{a}$ metade do século XVII", Anuario del Departamento de Historia y Teoría del Arte (U.A.M.), IX-X (1997-1998). p. 197-209, maxime p. 197.

${ }^{36}$ Arnaldo Sousa Melo, Maria do Carmo Ribeiro, "Os construtores das cidades: Braga e Porto (séculos XIV a XVI)" in Arnaldo Sousa Melo, Maria do Carmo Ribeiro, História da Construção. Os Construtores, Braga, CITCEM, 2011, p. 99-127, maxime p. 109.

${ }^{37}$ Saul António Gomes, D. Afonso V. O Africano, Lisboa, Círculo de Leitores, 2006, p. 121. 


\subsubsection{Ofícios da Defesa e da Caça}

Numa parte anterior deste trabalho, já se teve oportunidade de verificar que a Defesa tem um peso importante no âmbito da documentação que foi analisada. No entanto, pelo facto de muitas cartas enquadráveis nesse domínio serem ementas de subscrição régia, a participação dos oficiais da Milícia na burocracia não é tão significativa como se poderia supor.

O ofício de Anadel-mor foi regulamentado pelas Ordenações Afonsinas. Num dos raros exemplos de normas redigidas em estilo compilatório do Livro I deste código, determina-se que a este oficial competia, fundamentalmente, o apuramento, o provimento e a concessão de privilégios a diferentes tipos de besteiros (do monte, do cavalo, da câmara) ${ }^{38}$. Apesar de o regimento deste ofício não se encontrar em nenhum dos sistemas das Ordenações Manuelinas, na documentação analisada aparecem como redatores Anadéis-mores: dos besteiros do monte; dos besteiros do conto; dos besteiros da câmara; dos espingardeiros.

A intervenção burocrática destes oficiais não chega a abranger os $6 \%$ da documentação compulsada. A maior parte dos atos subscritos pelos Anadéis-mores são privilégios de natureza militar, que se enquadram no âmbito da Administração Geral. Para além disso, estes funcionários foram responsáveis pelo desembargo de algumas cartas de aposentação.

Ao Coudel-mor, ofício regulamentado pelas Ordenações Afonsinas, cabia prover os coudéis (responsáveis por grupos de cavaleiros) e os escrivães da coudelaria $^{39}$. Os atos subscritos por Francisco da Silveira, Coudel-mor, pelo menos, entre 1490 e 1530, confirmam as disposições normativas: este oficial foi responsável pela redação de 17 provimentos de ofício e duas cartas de aposentação de indivíduos integrados na esfera da coudelaria.

O Monteiro-mor era um oficial cujas atribuições se enquadravam no domínio da caça. Competia-lhe nomear os monteiros das comarcas, das câmaras e do monte e fiscalizar o exercício das suas funções, podendo também aposentá-los. Para além disso, era responsável pela cobrança de multas pela invasão das matas régias ${ }^{40}$. A participação dos Monteiros-mores na burocracia manuelina não era muito significativa em termos quantitativos, mas era constante.

${ }^{38}$ OA, L. I, tít. LXVIII, p. 405-421.

${ }^{39}$ OA, L. I, tít. LXXI, p. 473-520.

${ }^{40}$ OA, L. I, tít. LXVII, p. 398-405; Mário Alberto Nunes Costa, "O Arquivo da Montaria-Mor do Reino (1583-1833). Inventário preliminar”, Revista Portuguesa de História, XI (1964), p. 151-176, maxime p. 152; Isabel Bárbara de Castro Henriques, Os Caminhos do Desembargo: 1472, um ano na burocracia do "Africano", vol. I, dissertação de mestrado apresentada à FLUP, Porto, 2001. p. 136. 
Álvaro de Lima (1496), João de Lima $(1504,1512)$ e Luís de Meneses (1521) intervieram na redação de 24 cartas de provimento de ofício e de aposentação (sempre de monteiros).

\subsubsection{Ofícios da área da Física}

Apesar de a área da Física não constituir propriamente um 'departamento' da administração central, optou-se por considerá-la individualmente neste trabalho por dois motivos: porque a intervenção de Físicos-mores e Cirurgiões-mores na redação de diplomas em nome do Venturoso, não atingindo valores extraordinários, acaba por não ser insignificante; porque a Física não deixa de ser uma área de incidência governativa, enquadrável no âmbito da Administração Geral, dotada de oficiais próprios que tinham competências burocráticas específicas.

O ofício de Físico-mor, ao que tudo indica, costumava ser regulamentado no momento da nomeação titular ${ }^{41}$. O regimento passado a Diogo Lopes em fevereiro de 1521 determinava que lhe competia, entre outras coisas: examinar, através de provas teóricas e práticas, todos os físicos que exercessem no reino, inclusivamente estrangeiros (eram dispensados de apresentação a exames os que se formassem no Estudo Geral de Lisboa); emitir cartas de físico; exercer a jurisdição de execução de penas a quem praticasse a Medicina sem cumprir os pressupostos normativos ${ }^{42}$.

Nos registos consultados da Chancelaria do Venturoso só se encontra um tipo de carta cuja redação era responsabilidade do Físico-mor, a carta de físico. Os Mestres Afonso, António de Lucena e Rodrigo de Lucena e o Doutor Diogo Lopes subscreveram 21 atos deste género em 1496, 1504 e 1521.

Não tendo sido encontrada qualquer prescrição normativa sobre o exercício do ofício de Cirurgião-mor, resta apontar os reflexos da sua ação na atividade burocrática. Ao que tudo indica, as funções deste oficial seriam em tudo semelhantes às do Físico-mor: procederia ao exame dos cirurgiões e competir-lhe-ia emitir a carta que confirmasse a sua aptidão para o exercício da profissão de cirurgião. A intervenção burocrática dos Cirurgiões-mores era mais intensa do que a dos Físicos-mores, uma vez que se encontram 38 cartas de cirurgia subscritas por estes oficiais entre a documentação consultada.

${ }^{41}$ Aconteceu assim com Diogo Lopes, em 1521. Na sua carta de provimento diz-se que o seu antecessor, Mestre Afonso, também havia tido um regimento próprio, ligeiramente diferente. Cf. António Domingues de Sousa Costa (ed.), Chartularium Universitatis Portugalensis, vol. XII, Lisboa, Junta Nacional de Investigação Científica e Tecnológica, 1995, p. 39 (a partir daqui, CUP).

${ }^{42}$ CUP, vol. XII, p. 39-44. 


\subsection{Balanço}

A análise das normas que enformam os ofícios dos redatores de documentos da Chancelaria de D. Manuel I, associada ao seu confronto com as práticas evidenciadas pela atividade burocrática desses indivíduos, permitiu constatar que:

a) Descontando o desdobramento da Corregedoria da Corte em feitos cíveis e crimes, não há ofícios novos na administração do Venturoso;

b) O Chanceler-mor, os Vedores da Fazenda e os Desembargadores do Paço são os principais redatores de atos régios;

c) Não se encontra qualquer sinal de, durante o reinado de D. Manuel I, ter existido um Vice-Chanceler, ofício com algum peso nas Chancelarias de monarcas anteriores;

d) $\mathrm{O}$ Escrivão da Puridade, no que toca à produção burocrática registada na Chancelaria, eclipsou-se;

e) No domínio da Justiça, diminui o leque de magistrados com expressão no despacho de atos da Chancelaria;

f) Na Fazenda, não havendo novidades no que à criação de novos ofícios diz respeito, assiste-se à complexificação das funções dos Vedores.

Estes dados permitem corroborar ideias avançadas por Armando Luís de Carvalho Homem em 1997, na sequência da análise do Livro I do terceiro sistema das Ordenações Manuelinas:

a) Neste reinado não há "novidades acentuadas" no que toca à criação de ofícios;

b) Continua em curso o empobrecimento tipológico dos atos que são registados na Chancelaria régia; os documentos enquadráveis no domínio da Justiça acabam por desaparecer, "por força da multiplicação, entretanto registada, das instâncias de registo régias";

c) No que toca aos "trâmites da burocracia", nomeadamente no campo da Fazenda, parece ter havido inovações, apesar de apenas um exame mais aturado da documentação permitir confirmar as consequências práticas dos novos procedimentos administrativos ${ }^{43}$.

${ }^{43}$ Armando Luís de Carvalho Homem, "Ofício régio e serviço ao rei em finais do século XV: norma legal e prática institucional”, Revista da Faculdade de Letras. História, II série, 14 (1997), p. 123-137, maxime p. 128-131. 


\section{Conclusão}

O reinado de D. Manuel I durou 26 anos. Um pouco mais do que um quarto de século em que muita coisa mudou. Quando o Venturoso subiu ao trono, estava em curso o processo de 'descompartimentação do universo', que teve em Portugal uma das potências liderantes. D. Manuel foi um participante ativo e importante nas transformações desse tempo, e não um mero espectador atento que, felicíssimo na hora em que a Coroa que lhe fora parar às mãos (na sequência da morte de oito herdeiros mais diretos do Príncipe Perfeito), se limitara a deixar correr o que já estava em ação. Em 13 de dezembro de 1521 Portugal era um reino maior, mais rico e mais poderoso do que em 25 de outubro de 1495. Mas como é que estas mudanças se refletiram na Chancelaria, esse núcleo fundamental do governo do país?

Apenas chegou aos nossos dias uma pequena parte da burocracia que foi produzida pelo Desembargo de D. Manuel I: ao que tudo indica, menos de metade dos registos. Apesar disso, o que se conhece é suficiente para que se constate que foi durante o reinado do Venturoso que se operou uma transformação importante na forma como os atos eram organizados e arquivados na Chancelaria: da elaboração de cadernos em pergaminho, nos quais normalmente havia alguma coerência cronológica, que depois eram cosidos e reunidos num volume relativo a determinado ano, passou-se para a organização de tomos onde a maioria das cartas diz respeito a uma esfera da atividade burocrática. Assim surgiram livros de ofícios, livros de privilégios, livros de doações e livros de perdões (não sobra nenhum dos anos que foram analisados). Uma resposta eficaz ao aumento exponencial do número de registos da Chancelaria que se vinha verificando desde meados do século XV. Um reflexo evidente da progressiva especialização dos diferentes 'setores' da administração.

No que toca aos conteúdos dos diplomas, não há grandes novidades. Não surgem novas espécies documentais, mas há alterações importantes na correlação de forças de cada uma das áreas de incidência governativa no seio da Chancelaria. A Justiça eclipsa-se, na medida em que desaparecem as sentenças e as cartas de perdão. Não que tenham deixado de ser emitidas, mas devem ter sido copiadas para livros que não chegaram até nós. Na Administração Geral, o peso da Defesa é cada vez maior. E a Graça continua a atingir valores médios, não muito altos mas constantes, refletindo a liberalidade do monarca que faz mercê aos seus súbditos. O 'grande salto' acontece no domínio da Fazenda: no tempo de D. João II, menos de $9 \%$ da documentação emitida enquadrava-se neste 'departamento'; nos quatro anos estudados do reinado de D. Manuel, esse valor atinge os $50 \%$. 
Como era normal, D. Manuel interveio diretamente na preparação da burocracia régia. Damião de Góis traça-nos dele o retrato de um homem que gostava de despachar enquanto ouvia música e que tinha a preocupação de acompanhar diferentes momentos do processo administrativo. Quando se reunia com os seus oficiais, não gostava de deixar uma única petição por desembargar. O rei foi o responsável direto pela elaboração de cerca de $42 \%$ da documentação que foi analisada, mas este valor levanta reservas. Em termos absolutos, o Venturoso desembargava mais no domínio da Fazenda. No entanto, em termos relativos, é no âmbito da Graça que a intervenção direta do monarca mais se fazia sentir.

Relativamente aos cargos dos redatores da burocracia régia, não há novidades importantes. O Chanceler-mor, os Vedores da Fazenda e os Desembargadores do Paço são, para além do próprio rei, os principais responsáveis pela preparação dos diplomas. Tanto quanto foi possível apurar, D. Manuel não teve um Vice-Chanceler, e a participação do Escrivão da Puridade na redação de atos deixou de ser relevante. Ao que tudo indica, houve mudanças significativas no processo administrativo associado ao domínio da Fazenda, mas só um estudo aprofundado deste 'departamento' do governo manuelino poderá esclarecer isso cabalmente.

O quadro traçado permite constatar que a Chancelaria de D. Manuel I, tendo sofrido transformações, não foi palco de mudanças radicais. A sua estrutura externa foi o que mais mudou e, de alguma forma, representa a transição entre o modelo medieval de uma Chancelaria onde a organização dos livros é mais ou menos cronológica para um sistema moderno em que a cada volume corresponde determinado tipo de cartas. No que toca ao conteúdo dos documentos, não há novidades acentuadas, registando-se, no entanto, que os diplomas enquadráveis no domínio da Fazenda surgem em valores muito superiores ao que acontecia anteriormente. A estrutura da administração que é possível traçar a partir dos atos da Chancelaria não espelha qualquer reforma significativa.

Tenha o leitor em conta que tudo o que foi dito são conclusões baseadas na análise de oito livros de uma Chancelaria quem tem 47, correspondentes a quatro anos de um reinado que teve 26. As pistas que aqui são lançadas só poderão ser confirmadas ou infirmadas por estudos mais sistemáticos, mais aprofundados e mais abrangentes. 